\title{
Media Concentrations and Diversity
}

\author{
Dr. Prashant Kumar \\ Associate Professor, Department of Economics, Satyawati College (Eve.), University of Delhi, Delhi, India
}

\begin{abstract}
Often it is argued that high media concentrations (supply of media being dominated by a few firms in the industry) have an adverse impact on pluralism i.e. there is a negative correlation between extent of market domination and the levels of media diversity. However, the relationship between concentrations of media ownership and pluralism is not as simplistic. It does not consider the possibility that large organizations may be in a greater vantageposition, compared to their smaller counterparts, to engage in product innovation and to add to the range of media output thus facilitating pluralism. The implication is that, that concentrated media ownership could well be conducive to pluralism. This paper examines the issues relating to media concentrations and pluralism.
\end{abstract}

Key words:pluralism, horizontal and vertical integration, supply chain, media concentration

\section{INTRODUCTION}

In a general sense pluralism implies diversity in media, that is, the existence of diverse and numerous independent voices, presence of political opinions of differing hues and representation of the different cultures of the nation in the media.The Committee of Experts on Media Concentrations and Pluralism set up by the Council of Europe defines pluralism as follows:"media pluralism should be understood as diversity of media supply, reflected, for example, in the existence of a plurality of independent and autonomous media and a diversity of media contents available to the public" [1]. What this definition implies is that it is not so much about diversity in what is consumed by the public but diversity in what is offered to the public by the media firms. The definition of pluralism has two connotations -diversity of ownership and diversity of media content. Another way of looking at pluralism is in terms of 'external' and 'internal' pluralism. The former is said to be present when there is diversity of ownership whereas the latter exists when there is diversity in the output/content offered. At a broad level the idea of pluralism comprises of two aspects - political pluralism and cultural pluralism. Political pluralism requires the presence of differing political views and opinions, which is essential for a healthy democracy and the absence of which could pose a threat to democracy. Cultural pluralism emphasizes the need for expression, in the media, of a variety of cultures thus reflecting the diversity within society. This is important as its absence poses a threat to social cohesion.

\section{HOW MEDIA CONCENTRATIONS ARISE}

Media concentration implies that the supply of media is dominated by a few firms in the industry. High concentrations of media ownership is considered undesirable as it could lead to one sided over representation of certain political views and values and /or certain forms of cultural output (those favoured by the dominant media owners because of commercial considerations or ideological grounds) at the expense of others. However, it is not easy in practice to isolate the role of media ownership patterns in determining theextent of diverse media output that is made available to the public.Concentrations of media ownership can occur in different ways 'monomedia' concentration (horizontal expansion), cross-media concentration (vertical or diagonal integration or both). Horizontal merger occurs when two firms that are at the same stage in the supply chain or who are engaged in the same activity combine forces. For example, one television company acquires/merges with another television company. Horizontal expansion is a common strategy in sectors. It enables firms to expand their market share and achieve better and more efficient utilization of resources and exploit economies of scale. Vertical growth involves expanding either forward into downstream/succeeding stages or backward into upstream/preceding stages in the supply chain [2].Vertically integrated media firms could well be engaged in activities stretching from creation of media content/output (upstream stage) to distribution or retail (downstream stage) of that op. Vertical expansion generally results in reduced transaction costs for the enlarged firm. Another significant benefit of vertical integration is that it gives firms some control over their operating environment and it can help them to avoid losing market access in important upstream or downstream stages. An example of 
vertical expansion would be a film production company acquires or merges with a film distribution company or vice-versa. Diagonal expansion implies that firms diversify into new business areas,for example, a merger between a television company and a telecommunications operator. This could lead to or generate efficiency gains [3] as both types of services-audiovisual and telephony- are distributed jointly across the same communications infrastructure. Radio companies may diversify into magazine publishing or newspaper publishers may expand diagonally into television broadcasting.A host of possibilities exist for diagonal expansion across media and related industries. An importantbenefit of this strategy is that it helps to spread risk as the activities are now spread across different business areas.Further, due to expansion significant economies of scale and scope become available to the firm thus lowering production costs.

Logically it could be inferred that there is a negative correlation between extent of market domination (media concentration) and the level of media pluralism. Higher levels of media concentration implyless number of independent suppliers and consequently smaller range of output in any given market. A higher level of market domination means fewer competing suppliers and the latter implies less pluralism.

\section{DETERMINANTS OF MEDIA DIVERSITY}

However, the relationship between concentrations of media ownership and pluralism is not as simple as this[4]. Since the concept of pluralism includes both diversity of content and diversity of ownership, it is quite possible that large organizations may be better placed than small ones to engage in product innovation and to add to the diversity of media output. Hence, concentrated media ownership could actually be conducive to pluralism. High level of market domination implies fewer competing suppliers and fewer competing suppliers imply a more cost-efficient utilization of resources. The latter implies greater availability of resources for innovation which in turn would result in an increased range of output and hence greater pluralism. However, any specific market (as defined by product and location) can support only a certain level of supply. Thus, in smaller markets the relationship bet concentration and pluralism becomes complicated by the economic question - what level and composition of diversity is affordable. In short, the relationship between pluralism and media concentrations is complex, and both may be affected by a number of factors.

Size and wealth of market is an important factor affecting the level of diversity of content. In a free market economy, the amount of resources available to the media will essentially be limited primarily by the size and wealth of that economy, and the tendency on the part of the public to spend on or consume media. Expenditure on media products through direct payments will be constrained by the aggregate levels of consumer expenditure (which in turn is a function of the wealth of the economy).

The extent of earnings through advertising is also closely related to levels of consumer expenditureand economic wealth in a given market. Even in instances where the state intervenes to support an artificially high level of indigenous media provision, the level of such support too will be determined by the overall wealth of the economy, and of the competing claims for public expenditure.

It is, therefore, evident that the relationship bet the size and wealth of the market of an economy and the level of resources that could be allocated in supplying its media has unambiguous implications for pluralism. As many media outputpossess characteristics of 'public good', that is the product is not generally used up or destroyed in the act of its consumption, and the same unit can be offered to larger and larger audiences at an insignificantly low or zero marginal cost. Since it is the production of the first unit of media output that involves most of the costs incurred[5], a greater diversity in the composition of output would entail the employment of greater amount resources. Pluralism thus depends on the extent of resources available to support the origination and distribution of many different variety of media output. It is, therefore, contended that large and wealthy markets, which can afford greater resources for the provision of media, are likely to have a greater diversity of op than smaller markets. In general, the smaller level of resources available for media provision in small markets makes them prone to concentration of ownership. This though does not to mean that large markets necessarily avoid the problem of potentially undesirable concentrations of media ownership. However, as far as pluralism is concerned, it is not so much about the absolute size of media firms (in terms of turnover or profits) that is a relevant consideration but the extent to which they dominatethe market in which they operate. Big firms are likely to account for a large market share more easily in small than in large markets.

While wealthier markets are better placed to supply a more diversified output, the relationship between market wealth and pluralism is not so straight forward. An important intervening variable is the composition and structure of media supply. This is about the number of independent competing suppliers present in the market. Within the constraints imposed by the aggregate size and wealth of the market the existence of certain industrial structure would result in a more optimal use of resources available for media provision as compared to other structures. Hence, it is likely that a monopolistic industrial structure cloud provide greater diversity of media 
content/output, since economies of scale and scope are available to large media firms, than would be economically feasible in a more fragmented and competitive industry structure. On the other hand, a monopolistic industry structurecould result in a threat to pluralism as greater media power becomes concentrated in the hands of fewer suppliers.

Diversity of Suppliers or the number of separate independent suppliers in a market is anotherimportant determinant of media pluralism. As market concentrations rise as a result of monomedia or cross-media expansion, or vertical integration there is greater possibility of increasingly dwindling numbers of independent organizations involved in supplying media. The more powerful individual suppliers become, the greater the potential threat to pluralism. Here, it could be argued that regulations have been in place to create a measure of separation of ownership from editorial control and that it may not be necessarily true that higher concentrations of ownership would lead to lessercontent diversity. There has been much analysis and debate on this aspect and opinions are divided. The manner and extent to which ownership of a media organization couldinfluence the content of its products is therefore not clear. However, whatever the regulatory measures in place, the scope for owners of media firms to assert an indirect influence over the content and the message intended to be conveyed through their products, seem to be so comprehensive as to defy any absolute guarantees of separation. An owner's influence may manifest itself in various ways - in the choice of key personnel, in strategic decisions about which resources to reduce or invest more in and in arrangements for sourcing or distributing content. Since it is not easy to monitor the intentions of media owners, or to completely regulate their conduct in editorial matters, the most effective and practical way towards effectively ensuring a healthy diversity of opinions and voices in the media is to preclude media power from being monopolized and one way to achieve this is by making sure the presence of a large number of autonomous and independent suppliers of media.

\section{CONCLUSION}

It has been argued that the relationship between the relationship between pluralism and media concentrations is complex, and both may be affected by several factors. Diversity of media or media pluralism is influenced by a number of factors, such as size and wealth of market (extent of resources available to support the origination and distribution of many different variety of media output), composition and structure of media supply, diversity of suppliers, inter alia.Existence of greater concentrations per se may not imply lesser diversity. It is quite possible that large organizations may be better placed than small ones to engage in product innovation and to add to the diversity of media output and hence, concentrated media ownership could actually be conducive to pluralism. Further, the potential threat to pluralism increases as individual suppliers become more powerful. Regulatory measures aimed at creating separation between ownership and editorial control cannot ensure any absolute guarantee of separation as the owners can assert indirect influence in various ways. Since it is not easy to completely regulate the conduct of media owners in editorial matters orto monitor their intentions,the most effective and practical way to ensure diversity of opinions and voices in the media is to prevent monopolization of media power. This may be accomplished through ensuring the presence of a large number of autonomous and independent suppliers of media.

\section{REFERENCES}

[1] Doyle Gillian, Media Ownership, (London: Sage Publications Ltd., 2002) 12.

[2] Doyle Gillian,Understanding Media Economics,(London: Sage Publications Ltd., 2013) 19-22.

[3] A. Alexander, R. Carveth, J. Owers, C. Ann Hollifield, Albert N. Greco, (Ed.), Media Economics -Theory and Practice, (Mahwa, NJ: Lawrence Erlbaum Associates, 2004) 40.

[4] Beata Klimkiewicz, (Ed.), Media Freedom and Pluralism: Media Policy Challenges in the Enlarged Europe, (Budapest: Central European University Press, 2010) 261.

[5] David Hesmondhalgh, The Cultural Industries, (London: Sage Publications Ltd., 2007) 168. 